\title{
Health care policy and journal impact
}

\author{
William A. Van Decker, $M^{a}$ \\ a Temple University School of Medicine, Philadelphia, PA \\ Received Jun 1, 2015; accepted Jun 1, 2015 \\ doi: 10.1007/s12350-015-0200-x
}

\begin{abstract}
"What we have before us are some breathtaking opportunities disguised as insoluble problems."

John W. Gardner, Secretary Health, Education, Welfare 1965

A recent commencement speaker reminded his audience of these words from John Gardner, a Lyndon Johnson cabinet member whose job would currently have been labeled as Secretary Health Human Services (HHS). Timeless words of inspiration that can be used to urge each generation to look at any challenges before it not as end-stage gridlock and chronic forever problems to be depressingly cursed but instead as a breathtaking opportunity awaiting passionate innovative fixes. Nevertheless, we should recognize that Gardner was specifically referring to the care of the retired elderly in this nation and his personal daunting task of implementing the Medicare Act of 1964. Fast forward 50 years and healthcare appears on surface oh so much more complicated, yet the very basic concepts of quality, access, and cost remain oh so relevant and unchanged. Current complexities and scope lead many to curse the darkness of current Health Policy sound bites: Affordable Care Act (ACA), Medicare Access and CHIP Reauthorization Act of 2015 ("MACRA"), Alternate Payment Models (APM), etc., but Gardner's words remain applicable.

Health Care Policy is forever an integration of hard medical science on population and individual patient health in a nation which works on financial incentives (but in a less than perfect market), champions individual choice, currently allows diverse healthcare delivery venues, and does not practice steady-state population control. As the population grows and demographics change (currently aging), challenges are bound to surface. According to 2013 CMS statistics, in 1966, 19.1
\end{abstract}

Reprint requests: William A. Van Decker, MD, Temple University School of Medicine, 3401 North Broad Street, Philadelphia, PA 19140; william.vandecker@tuhs.temple.edu

J Nucl Cardiol 2015;22:594-6.

$1071-3581 / \$ 34.00$

Copyright (c) 2015 American Society of Nuclear Cardiology. million people were enrolled in Medicare. In 2013, 52.3 million were in Medicare (and also another 57.4 million in Medicaid which in total creates the government as a large player in the health insurance market). Some statistics project that in 2050, 95 million people will be enrolled in Medicare alone. In 2012, CMS spent 732.4 billion in care (20.7\% of the federal budget). Moreover, the Social Security Office of the Chief Actuary projects increasing life expectances after age 65 once having obtained that milestone. In 1965 that expectancy was 12.9 years for males and 16.3 for females, in 2010 17.6 years for males and 20.2 years for females, and in 2050 is projected to be 20.7 years for males and 22.8 years for females. ${ }^{1}$ Additionally, looking at just ischemic heart disease, the prevalence of coronary atherosclerosis in this nation and with aging is very high. MESA Coronary Calcium Data suggest the presence of coronary artery disease by a non-zero calcium score to be $77 \%$ in white males age 65 and $90 \%$ by the time they are age $75,47 \%$ in white females age 65 and $73 \%$ by age $75,56 \%$ in black males at age 65 and $75 \%$ at age 75 , $37 \%$ in black females at age 65 and $62 \%$ at age $75,64 \%$ in Hispanic males at age 65 and $84 \%$ at age 75 , and $38 \%$ for Hispanic females at age 65 and $62 \%$ at age $75 .^{2}$

Given the above realities, healthcare population statistics and cost are bound to be the predominant national discussion for the next quarter century at least as a US population estimated by the census bureau in 2015 of 321 Million grows to 398 Million in 2050 by projection.

The pragmatic current discussions to deal with "insoluble problems" in HealthCare Policy fall into two evolving realms: Quality Incentive Models and Alternate Payment Models (which overlap in many ways and what some see as a continuum) both of which were accelerated by the SGR Repeal Bill (MACRA). These discussions pay homage to the NYC concept of "Valuation" (where upfront cost is only one piece of return on investment). Value $=$ quality divided by cost.

Quality Incentive Models which soon will affect the field of nuclear cardiology include first the AUC mandate for Medicare stipulated by the SGR Patch Bill of 
2014. Medicare will settle on AUC for all Advanced Imaging from a variety of stakeholder submissions in Nov. 2015 and a Clinical Decision Support (CDS) tool(s) by April 2016 for implementation Jan 2017. Ordering providers will need proof they consulted a CDS tool in ordering. While no penalties or denials start the process, data are gathered on appropriateness electronically with the goal of instituting a pre-authorization program for providers in the bottom 5\% of appropriate ordering. From the Nuclear Cardiology perspective, it is vital that no test substitutions occur because of unleveled playing fields and unintended consequences. The rest of the CMS Quality Program was dramatically changed with the passage of the MACRA SGR Fix Legislation. By 2019, the "Merit Based Incentive Payment System" (MIPS) will replace by combining Physician Reporting System (PQRS)-30\%, Electronic Health Record (EHR) Meaningful USE (MU)-25\%, and the Value-Based Modifier (VBM)-30\% with added clinical practice improvement activities-15\%. Reporting will be encouraged through EHR or Qualified Clinical Data Registries (QCDR). Utilizing a QCDR will also qualify as a practice improvement activity. (ASNC's ImageGuide Registry recently achieved QCDR status with CMS.) Penalties for being below threshold will be $4 \%$ in 2019 and go to $9 \%$ in 2022 and beyond. Bonus incentives for being above threshold will be equal to penalties in a zero-sum game, suggesting some practices could be potentially separated by $18 \%$ for similar services. The Secretary must develop and post a draft plan for Quality Measure Development for comment on Jan 2016 and accept comments till March 2016. The final MIPS measures will be issued in Nov 2016.

The MAJOR impact of the MACRA will be the acceleration of Alternative Payment Models (APMs) which are the current perceived answer to SGR. Financial incentives will push providers toward exploring new models beyond fee for service. ALL of these models will essentially test provider RISK SHARING in payment. Models are likely to include Accountable Care Organizations (ACOs) and Episode of Care Models (EOC). While it is easier to conceive of EOC models based on elective surgical procedures, risk sharing in complex cardiac care scenarios such as acute myocardial infarction, congestive heart failure, and chest pain without the safety net of outlier carve outs will certainly lead to more angst. MACRA creates an advisory panel to consider physician proposals for new models. By Nov 2016, the secretary must establish criteria for the panel to use in making recommendations on APMs. By July 2017, MEDPAC must submit a report to Congress on how physician spending and ordering patterns impact spending under Parts A, B, D and a final report is due July 2021.

Okay, interesting say some, but why this discussion in a medical scientific Journal? Some would argue to separate the Science of Medicine from the Business of Medicine entirely and some others would argue that philosophical policy "Washington-type" arguments/ discussions of health care delivery are warranted in a scientific medical Journal but pragmatic operational details should stay in other forums (especially since large health organizations are usually reluctant to share business models/data in an environment rapidly leading to hospital mergers and acquisitions for market share to survive the possible upcoming RISK-SHARING contract bidding wars). Certainly ACC Advocacy Committee, ASNC Health Policy Committee, and the other CV societies all have committees digesting all this information and formulating input.

True, BUT ... I would submit that Good Health Care Policy Outcomes come from Good EvidenceBased Medical Science only if Incentives are in place that appropriately support Good Evidence-Based Medical Science to be delivered. I would also submit that in the Art of Nuclear Cardiology the only way we recognize what is good medical science is by critically publishing and reviewing many scientifically driven research/data manuscripts in the translational sciences of Image Quality; Quality Clinical Patient Outcomes (and what are the EXACT nuclear cardiology parameters of a given patient-young or "older," patient, time, and clinical presentation that lead to that improved clinical decision outcome); episode of care management and clinical outcomes (including readmissions) immediately, 30 days later, one year later, and two years later; protocols to decrease cost while increasing Valuation; explorations of the utility of nuclear cardiology in EOC management beyond Ischemic heart Disease and diagnosis of chest symptoms; and its outcome utility in chronic long-term disease management. I would submit that a Registry offers a potential platform for exploring these key issues but the "making operational" presents some challenges as well. I would also submit that the growth of Nuclear Cardiology in the 1990s and 2000s was driven by strong patient outcome data gleaned from a plethora of clinical manuscripts which led to easy construction of AUC criteria and by innovative solutions to significant challenges such as physician credentialing and lab accreditation. Finally, I would submit that a pragmatic person from North Jersey might suggest that "Valuation" is built by a community meticulously and unrelentingly building and promulgating scientific information to prove its relative worth (because if a community does not see that as part of its purpose, there 
will be no lack of others arguing for devaluation-a community must be part of the conversation).

The Journal of Nuclear Cardiology (JNC) can have an important "impact" by showcasing important manuscripts that build on the field's Valuation to Patient-Centered Care and Outcomes and can hopefully generate enough internal discussion within the field to lead to centripetal expansion of manuscripts into other science journal venues as well.

Enough of my submissions, the Journal does encourage submissions from the talented community to continue to build and enhance the scientific case for the clinical Valuation of the field based on cost-effective quality outcomes. Breathtaking opportunities should never be wasted.

\section{References}

1. http://www.cms.gov/Research-Statistics-Data-and-Systems/Research/ ResearcgGenInfo/CMSStatistics.html

2. www.mesa.nhlbi.org/cacreference.aspx 